Original Research Article

\title{
Safety and treatment adherence of commonly prescribed typical and atypical antipsychotics in schizophrenic patients in a tertiary care hospital
}

\author{
Lavanya Nagaraj, Naveen Kumar Madalageri*
}

Department of Pharmacology, Sree Narayana Institute of Medical Science, Ernakulam, Kerala, India

Received: 10 November 2016 Accepted: 14 November 2016

\section{*Correspondence to:}

Dr. Naveen Kumar Madalageri, Email: dr.naveen.madalageri@ gmail.com

Copyright: () the author(s), publisher and licensee Medip Academy. This is an openaccess article distributed under the terms of the Creative Commons Attribution NonCommercial License, which permits unrestricted noncommercial use, distribution, and reproduction in any medium, provided the original work is properly cited

\begin{abstract}
Background: Schizophrenia is a chronic mental disorder characterized by delusions, hallucinations, incoherence and physical agitation. Presently available drugs in the treatment of Schizophrenia are typical and atypical antipsychotics which act on various neurotransmitters like Dopamine, Serotonin and Acetylcholine. Though both classes of drugs are effective in treatment, they differ in tolerability and treatment adherence. Hence present study has been taken to compare safety and treatment adherence of typical and atypical antipsychotics.

Methods: It was a comparative study conducted on 90 patients of Schizophrenia for one year. The study subjects were randomly assigned into 3 groups of 30 patients each. Group 1 were treated with Risperidone, group 2 with Olanzapineand and group 3 with Haloperidol. Safety was measured by Abnormal involuntary movement scale, Barnes akathisia scale, Simpson angus scale and pattern of adverse effects in each group. Treatment adherence was measured by number of dropout subjects and pill count.

Results: Barnes akathisia scale and Simpson angus scale showed one point improvement in Risperidone and Olanzapine group where as one point worsening in haloperidol group. Abnormal involuntary movement scale showed low scores in haloperidol group. Extra Pyramidal symptoms were more common adverse effect in Haloperidol group where as weight gain in Olanzapine and Risperidone group. Pill count was more in Olanzapine group than Risperidone and Haloperidol group.

Conclusions: The adverse effect like extrapyramidal symptoms is more common among haloperidol. Weight gain was common in olanzapine treated patients than Risperidone treated patients but treatment adherence was better in Olanzapine treated patients.
\end{abstract}

Keywords: Efficacy, Haloperidol, Olanzapine, Risperidone, Schizophrenia, Treatment adherence

\section{INTRODUCTION}

Schizophrenia is a chronic mental disorder characterized by delusions, hallucinations, incoherence and physical agitation. ${ }^{1}$ Schizophrenia affects $1 \%$ of the population and ranks among the top 10 causes of disability worldwide; in India prevalence is $2.3 / 1000$ population and thus it imposes a heavy burden on the patient, their family and society. ${ }^{2}$

It is a heterogeneous psychiatric disorder due to variation in neurotransmitters like dopamine, serotonin, acetylcholine and glutamate. The symptoms of
Schizophrenia includes positive symptoms like delusions, hallucinations, grossly disorganised thought, agitation and negative symptoms like alogia, flattened affect, anhedonia and avolition. While positive symptoms are most amenable to the treatment there is no effective treatment available for negative and cognitive symptoms. $^{2}$

Presently available drugs in the treatment of Schizophrenia like typical antipsychotics mainly act on dopamine system and newer drugs act on dopamine as well as other neurotransmitter systems like serotonin, acetylcholine etc. $^{3}$ 
The treatment of schizophrenia remains an enormous challenge. Typical antipsychotic medications like haloperidol, chlorpromazine and trifluperazine are shown to suppress the acute psychotic symptoms of schizophrenia and prevent their recurrence. However, many patients with chronic disorders were found to be unresponsive to these antipsychotic drugs, and it was generally believed that, despite the ability of these drugs to suppress acute psychotic symptoms and prevent relapse, they did not positively change the long-term course of the disorder or subsequently improve outcome. Moreover, typical antipsychotic drugs were associated with high rates of neurological side effects (i.e., acute extra pyramidal signs and tardive dyskinesia) that compromised the therapeutic effects of treatment and impelled many patients to discontinue their use, thus increasing the risk for relapse. ${ }^{4}$

Introduction of atypical antipsychotics like risperidone, olanzapine and clozapine have been heralded as a therapeutic advance in its management, accounting for over $2 / 3^{\text {rd }}$ of all antipsychotic drug prescription. Atypical antipsychotics affect a broader range of Schizophrenic psychopathology and are generally better tolerated than conventional antipsychotics. ${ }^{4,5}$

Studies comparing typical and atypical antipsychotic drug showed equal efficacy or, at most modest therapeutic superiority for the atypical drug in positive, negative, cognitive and mood symptoms, have lower risk of extra pyramidal adverse effects, which improves patient compliance. But it needs to be balanced against the problems of weight gain, dyslipidemia and hyperglycaemia which constitute part of metabolic syndrome. ${ }^{5,6}$

As there is paucity of data in Indian population the present study has been taken up to evaluate the safety and treatment adherence of commonly prescribed typical and atypical antipsychotics in schizophrenic patients in a tertiary care hospital.

\section{METHODS}

A prospective observational study was conducted in the department of psychiatry, Victoria hospital, Bangalore during Jan 2010- June 2011 using purposive sampling with 90 patients with schizophrenia.

After obtaining approval and clearance from the institution ethical committee, patients were included for the study.

The study subjects fulfilling the inclusion/exclusion criteria were randomly assigned into 3 groups of 30 patients in each group.

Group 1: Patients treated with risperidone (oral dose 0.25 to $4 \mathrm{mg}$ ).
Group 2: Patients treated with olanzapine (oral dose 2.5 $\mathrm{mg}$ to $20 \mathrm{mg}$ ).

Group 3: patient treated with haloperidol (oral doses 1 $\mathrm{mg}$ to $10 \mathrm{mg}$ ).

\section{Inclusion criteria}

Patients of either sex aged between 18-65years suffering from schizophrenia.

- Patients who fulfilled the criteria of ICD-10 (International Classification of Disease-10, WHO1992).

- Patients in the respective groups who were on treatment with that particular drug for a minimum duration of 3 months.

Patients who gave Written informed consent.

\section{Exclusion criteria}

Patients who received more than one antipsychotic medication and who had received them in the past one year.

Patient with major psychiatric illness.

Patients with co-morbid medical conditions like Diabetes mellitus, Dyslipidemia, Coronary heart disease, Hypertension, Parkinson disease.

- Patient with concomitant physical illness.

- Presence of alcohol and substance abuse/dependence, epilepsy, mental retardation, mental disorders other than schizophrenia.

- $\quad$ Patient suffering from any major endocrine disorders.

- Pregnant and lactating women.

- Non-compliant patients who were unable to give consent for the study.

\section{Study procedure}

Inpatients as well as outpatients at the department of psychiatry diagnosed to be suffering from schizophrenia using ICD-10 criteria and fulfilling the inclusion/ exclusion criteria were taken into the study after obtaining written informed consent.

A thorough physical/ psychiatric evaluation were carried out and recorded in the protocol. Vital signs like body weight, body mass index (BMI), waist hip ratio, pulse rate, heart rate and blood pressure were recorded. 
Extra pyramidal symptoms was evaluated with

- Abnormal involuntary movement scale (Annexure-1)

- Barnes akathisia scale (Annexure-2)

- $\quad$ Simpson angus scale (Annexure-3)

\section{Treatment adherence: was assessed by}

- Number of drop out cases

- Pill count

\section{The detailed schedule of patient visit is as follows:}

\section{Visit 1/day1/initial or baseline assessment}

$\checkmark$ Patients were informed fully about the purpose and requirements of the study and written informed consent will be obtained.

$\checkmark \quad$ Patients were enrolled as per protocol criteria.

$\checkmark$ Details of patient's demographic characteristic, medical history, concomitant medication, pill count and detailed physical/psychiatric evaluation were recorded.

$\checkmark$ Blood samples for relevant baseline laboratory investigations were collected.

$\checkmark$ Concomitant use of anticholinergics, selective serotonin reuptake inhibitors, benzodiazepines and electroconvulsive therapy are permitted as and when needed.

$\checkmark$ Patients were issued medication once every month and instructed for regular follow up there after.

Visit $2 / 3^{\text {rd }}$ month

$\checkmark \quad$ Medication compliance, pill count, any intercurrent illness or change in concomitant medications were recorded.

$\checkmark \quad$ All observed or spontaneously volunteered adverse events were recorded.

$\checkmark$ A thorough physical/ psychiatric evaluation was carried out and recorded.

$\checkmark$ Visit $3 / 6^{\text {th }}$ month-

$\checkmark \quad$ Medication compliance, pill count, any intercurrent illness or change in concomitant medication were recorded.

$\checkmark$ All observed or spontaneously volunteered adverse events were recorded.

$\checkmark$ A thorough physical/ psychiatric evaluation was carried out and recorded.

$\checkmark$ Blood samples for relevant laboratory investigations were collected.

Visit $4 / 9^{\text {th }}$ month $\checkmark \quad$ Medication compliance, pill count, any intercurrent illness or change in concomitant medications were recorded.

$\checkmark \quad$ All observed or spontaneously volunteered adverse events were recorded.

$\checkmark$ A thorough physical/psychiatric evaluation was carried out and recorded.

Visit 5/1 year

$\checkmark \quad$ Medication compliance, pill count, any intercurrent illness or change in concomitant medications were recorded.

$\checkmark$ All observed or spontaneously volunteered adverse events were recorded.

$\checkmark$ A thorough clinical/ psychiatric examination was repeated.

$\checkmark$ Blood samples for relevant laboratory investigations were collected.

$\checkmark \quad$ The study termination form was completed.

$\checkmark$ If any adverse event is persistent or there is any abnormal laboratory value of clinical significance appropriate follow up was made and patients were advised about further therapy.

\section{Statistical methods}

Descriptive statistical analysis has been carried out in the present study. Results on continuous measurements are presented on Mean \pm SD (Min-Max) and results on categorical measurements are presented in Number (\%). Significance is assessed at $5 \%$ level of significance. The following assumptions on data is made,

\section{Assumptions}

1. Dependent variables should be normally distributed.

2. Samples drawn from the population should be random, and Cases of the samples should be independent.

\section{Significant figures}

+ Suggestive significance (P value: $0.05<\mathrm{P}<0.10)$

* Moderately significant ( $\mathrm{P}$ value: $0.01<\mathrm{P} \leq 0.05$ )

** Strongly significant ( $\mathrm{P}$ value: $\mathrm{P} \leq 0.01$ )

\section{RESULTS}

Totally 90 patients suffering from schizophrenia on antipsychotic medications were included in this study. Out of 90 patients, at follow up there were 3 drop outs in haloperidol group. Among 3 drop outs, 2 were noncompliant with the treatment in visit1 and in visit 2 , one patient did not report for follow up. These 3 patients were 
excluded from the data analysis and 3 new patients were included to complete the study.

\section{Safety evaluation}

\section{BARS (Barnes akathisia rating scale) (Table land Figure 1)}

The change in Barnes akathisia rating scale from baseline to endpoint reflected a 1 point improvement in extra pyramidal symptoms among the risperidone group and
Olanzapine group. There was one point worsening among the haloperidol treated patients with $\mathrm{p}<0.001$.

\section{AIMS (Abnormal involuntary movement scale) (Table 1 and Figure 2)}

There was statistically significant reduction in AIMS score in Group III with $\mathrm{p}<0.001 * *$. Abnormal Involuntary Movements were not seen with group I and group II, thus the score is 0 in both the groups.

Table 1: Psychiatric evaluation of study subjects Barnes akathisia rating scale, abnormal involuntary movement scale and Simpson Angus scale.

\begin{tabular}{|c|c|c|c|c|c|c|c|}
\hline \multirow{2}{*}{$\begin{array}{l}\text { Safety } \\
\text { evaluation }\end{array}$} & \multirow{2}{*}{$\begin{array}{l}\text { Group I } \\
\text { (Risperidone) }\end{array}$} & \multirow{2}{*}{$\begin{array}{l}\text { Group II } \\
\text { (Olanzapine) }\end{array}$} & \multirow{2}{*}{$\begin{array}{l}\text { Group III } \\
\text { (Haloperidol) }\end{array}$} & \multirow{2}{*}{$\begin{array}{l}\text { Overall } \\
\text { P value }\end{array}$} & \multicolumn{3}{|c|}{ Pair wise comparison } \\
\hline & & & & & I-II & I-III & II-III \\
\hline \multicolumn{8}{|l|}{ BARS } \\
\hline Visit 1 & $0.80 \pm 0.41$ & $0.77 \pm 0.43$ & $1.63 \pm 1.45$ & $0.059+$ & 0.989 & $0.002 * *$ & $0.001 * *$ \\
\hline Visit 2 & $0.43 \pm 0.5$ & $0.53 \pm 0.51$ & $1.17 \pm 1.26$ & $0.097+$ & 0.889 & $0.003 * *$ & $0.012 *$ \\
\hline Visit 3 & $0.17 \pm 0.38$ & $0.17 \pm 0.38$ & $0.83 \pm 1.09$ & $0.011 *$ & 1.000 & $0.001 * *$ & $0.001 * *$ \\
\hline Visit 4 & $0.03 \pm 0.18$ & $0.03 \pm 0.18$ & $0.67 \pm 0.92$ & $<0.001 * *$ & 1.000 & $<0.001 * *$ & $<0.001 * *$ \\
\hline Visit 5 & 0 & $0.03 \pm 0.18$ & $0.43 \pm 0.68$ & $<0.001 * *$ & 0.946 & $<0.001 * *$ & $<0.001 * *$ \\
\hline \multicolumn{8}{|l|}{ AIMS } \\
\hline Visit 1 & 0 & 0 & $4.57 \pm 5.51$ & $<0.001 * *$ & 1.000 & $<0.001 * *$ & $<0.001 * *$ \\
\hline Visit 2 & 0 & 0 & $3.57 \pm 4.56$ & $<0.001 * *$ & 1.000 & $<0.001 * *$ & $<0.001 * *$ \\
\hline Visit 3 & 0 & 0 & $2.77 \pm 3.76$ & $<0.001 * *$ & 1.000 & $<0.001 * *$ & $<0.001 * *$ \\
\hline Visit 4 & 0 & 0 & $1.50 \pm 2.18$ & $<0.001 * *$ & 1.000 & $<0.001 * *$ & $<0.001 * *$ \\
\hline Visit 5 & 0 & 0 & $0.67 \pm 1.21$ & $<0.001 * *$ & 1.000 & $<0.001 * *$ & $<0.001 * *$ \\
\hline \multicolumn{8}{|l|}{ SAS } \\
\hline Visit 1 & $0.63 \pm 0.49$ & $0.83 \pm 0.38$ & $3.63 \pm 4.80$ & 0.324 & 0.944 & $<0.001 * *$ & $0.001 * *$ \\
\hline Visit 2 & $0.33 \pm 0.48$ & $0.43 \pm 0.50$ & $2.60 \pm 3.52$ & 0.257 & 0.981 & $<0.001 * *$ & $<0.001 * *$ \\
\hline Visit 3 & $0.07 \pm 0.25$ & $0.13 \pm 0.35$ & $1.67 \pm 2.25$ & $0.001 * *$ & 0.979 & $<0.001 * *$ & $<0.001 * *$ \\
\hline Visit 4 & 0 & 0 & $0.93 \pm 1.59$ & $<0.001 * *$ & 1.000 & $0.001 * *$ & $0.001 * *$ \\
\hline Visit 5 & 0 & 0 & $0.50 \pm 0.97$ & $0.001 * *$ & 1.000 & $0.003 * *$ & $0.003 * *$ \\
\hline
\end{tabular}

\section{SAS (Simpson Angus scale) (Table land Figure 3)}

The change in Simpson Angus scale from baseline to endpoint reflected a 1 point improvement in extra pyramidal symptoms among the group 1 and 2 and 1 point worsening among the haloperidol treated patients with $\mathrm{p}<0.001$.

\section{Adverse drug reaction in each groups (Table 2)}

In Risperidone group (Figure 4) - weight gain (46.7\%) followed by constipation $(23.3 \%)$, increased appetite (16.7\%), Nasal congestion (16.7\%) and least common tremors $(6.7 \%)$ and Dry mouth $(6.7 \%)$.

In Olanzapine group (Figure 5) - weight gain $(66.7 \%)$ followed by increased appetite $(46.7 \%)$, constipation $(43.3 \%)$, dizziness $(43.3 \%)$ and least common fatigue and dry mouth $(3.3 \%)$.
In Haloperidol group (Figure 6) - EPS and tremors $(36.7 \%)$ followed by fatigue $(23.3 \%)$, Somnolence $(16.7 \%)$ and least common insomnia (13.3\%). In our study the commonly observed EPS were tremors, abnormal gait, and dystonia.

Weight changes among the study subjects

Table 3 and Figure7: shows weight changes among the study subjects. In group I (Risperidone) there was mean increase in the weight from baseline $59.70 \pm 5.27$ to last follow up $62.37 \pm 6.01$ with mean difference of $2.67 \pm 2.63$. In group II (Olanzapine) there was mean increase in the weight from baseline $59.60 \pm 4.74$ to last follow up $63.93 \pm 6.95$ with mean difference of $4.33 \pm 2.93$. In group III (Haloperidol) there was no increase in the weight from baseline $61.20 \pm 7.27$ to last follow up $61.20 \pm 7.27$ with mean difference of $0.43 \pm 1.30$. There was statistically 
significant ( $\mathrm{p}<0.001 * *$ ) increase in body weight from baseline to last follow up with group I and group II.

Table 2: Adverse effects among study subjects.

\begin{tabular}{|llll|}
\hline $\begin{array}{l}\text { Adverse } \\
\text { effect }\end{array}$ & $\begin{array}{l}\text { Group I } \\
\text { (risperidone) } \\
(\mathbf{n = 3 0})\end{array}$ & $\begin{array}{l}\text { Group II } \\
\text { (olanzapine) } \\
(\mathbf{n = 3 0})\end{array}$ & $\begin{array}{l}\text { Group III } \\
\text { (haloperidol) } \\
(\mathbf{n = 3 0})\end{array}$ \\
\hline Fatigue & 0 & $1(3.3 \%)$ & $7(23.3 \%)$ \\
\hline Dry mouth & $2(6.7 \%)$ & $1(3.3 \%)$ & 0 \\
\hline $\begin{array}{l}\text { Nasal } \\
\text { congestion }\end{array}$ & $5(16.7 \%)$ & 0 & 0 \\
\hline Constipation & $7(23.3 \%)$ & $13(43.3 \%)$ & 0 \\
\hline $\begin{array}{l}\text { Increased } \\
\text { appetite }\end{array}$ & $5(16.7 \%)$ & $14(46.7 \%)$ & 0 \\
\hline Weight gain & $14(46.7 \%)$ & $20(66.7 \%)$ & 0 \\
\hline Insomnia & 0 & 0 & $4(13.3 \%)$ \\
\hline Somnolence & 0 & 0 & $5(16.7 \%)$ \\
\hline Dizziness & 0 & $13(43.3 \%)$ & 0 \\
\hline Tremors & $2(6.7 \%)$ & 0 & $11(36.7 \%)$ \\
\hline EPS & 0 & 0 & $11(36.7 \%)$ \\
\hline
\end{tabular}

Table 3: Weight changes among the study subjects.

\begin{tabular}{|llll|}
\hline $\begin{array}{l}\text { Weight } \\
(\mathrm{kg})\end{array}$ & $\begin{array}{l}\text { Group I } \\
\text { (Risperidone) }\end{array}$ & $\begin{array}{l}\text { Group II } \\
\text { (Olanzapine) }\end{array}$ & $\begin{array}{l}\text { Group III } \\
\text { (Haloperidol) }\end{array}$ \\
\hline $\begin{array}{l}\text { Pre- } \\
\text { treatment }\end{array}$ & $59.70 \pm 5.27$ & $59.60 \pm 4.74$ & $61.20 \pm 7.27$ \\
\hline $\begin{array}{l}\text { Post } \\
\text { treatment }\end{array}$ & $62.37 \pm 6.01$ & $63.93 \pm 6.95$ & $61.20 \pm 7.27$ \\
\hline $\begin{array}{l}\text { Mean } \\
\text { difference }\end{array}$ & $2.67 \pm 2.63$ & $4.33 \pm 2.93$ & $0.43 \pm 1.30$ \\
\hline P value & $<0.001 * *$ & $<0.001 * *$ & $0.079+$ \\
\hline
\end{tabular}

Table 4: Medication adherence by pill count.

\begin{tabular}{|lllllll|}
\hline $\begin{array}{l}\text { Assessment } \\
\text { method }\end{array}$ & \multicolumn{2}{l}{$\begin{array}{l}\text { Group I } \\
\text { (risperidone) }\end{array}$} & \multicolumn{2}{l|}{$\begin{array}{l}\text { Group II } \\
\text { (olanzapine) }\end{array}$} & \multicolumn{2}{l|}{$\begin{array}{l}\text { Group III } \\
\text { (haloperidol) }\end{array}$} \\
\hline Pill count & No & \% & No & \% & No & \% \\
\hline
\end{tabular}

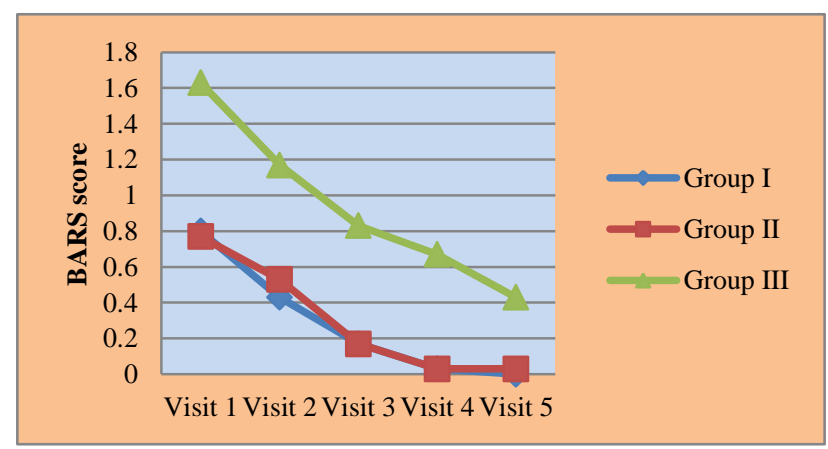

Figure 1: Psychiatric evaluation of study subjects in Barnes akathisia rating scale.

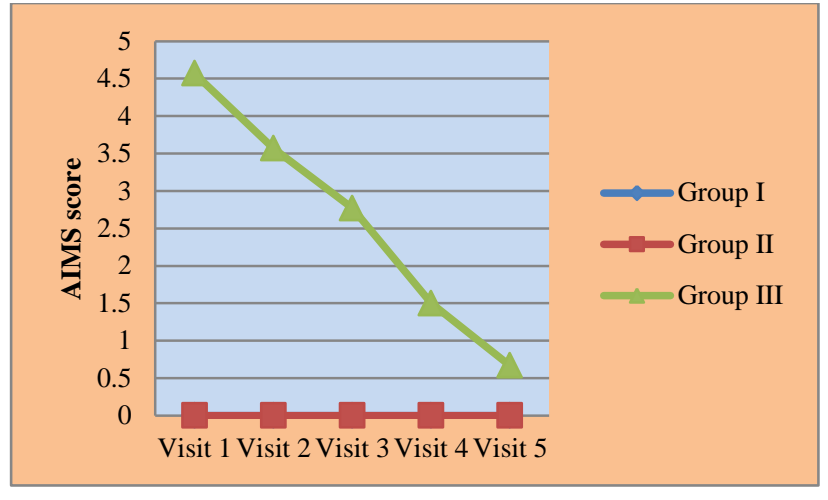

Figure 2: Psychiatric evaluation of study subjects in abnormal involuntary movement scale.

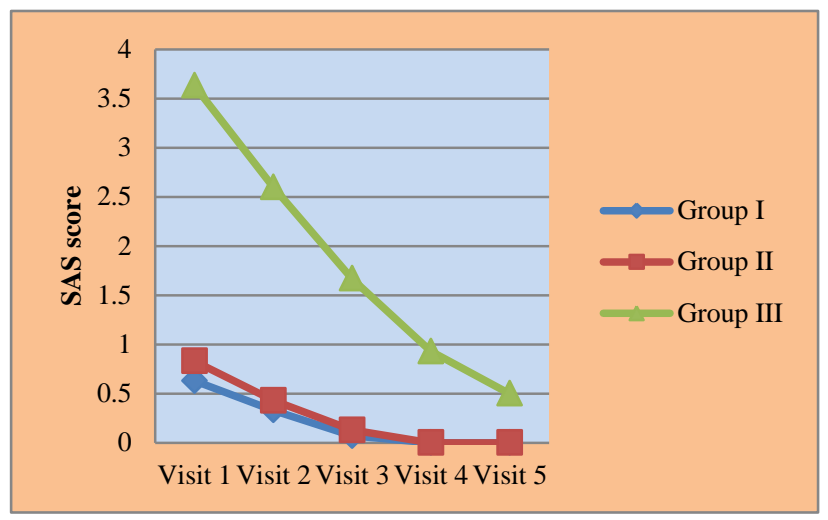

Figure 3: Psychiatric evaluation of study subjects in Simpson Angus scale.

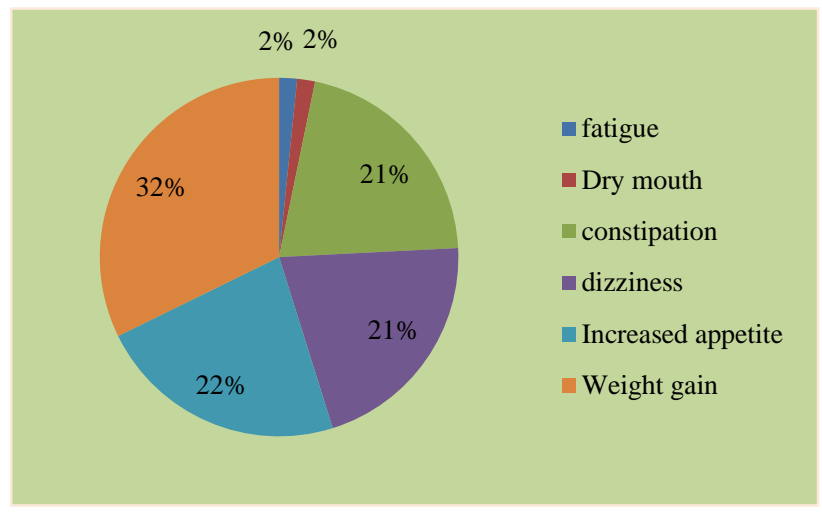

Figure 4: Adverse effects in risperidone group.

\section{Treatment adherence}

Table 4: Summarizes medication adherence by pill count. $93.33 \%$ of patients were adherent in group II (Olanzapine) and 90\% with group I (Risperidone) and $83.33 \%$ with group III (Haloperidol). 


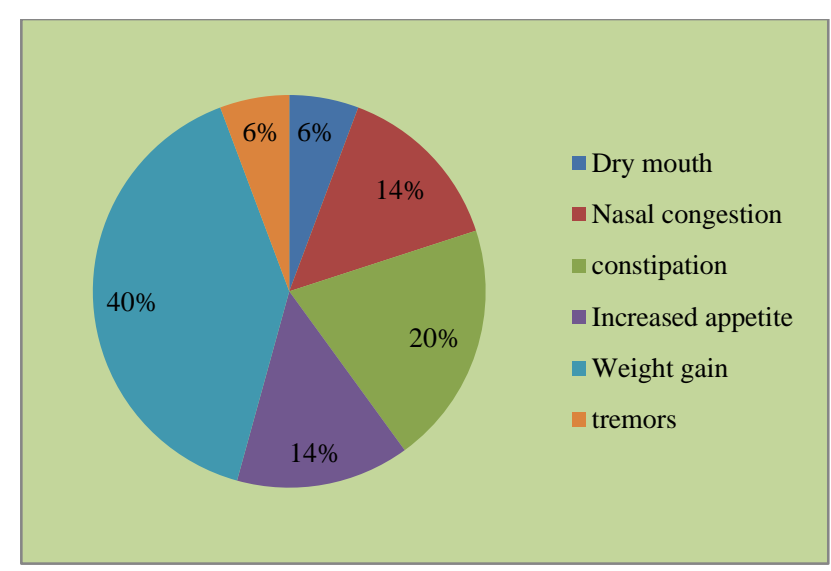

Figure 5: Adverse effects in olanzapine group.

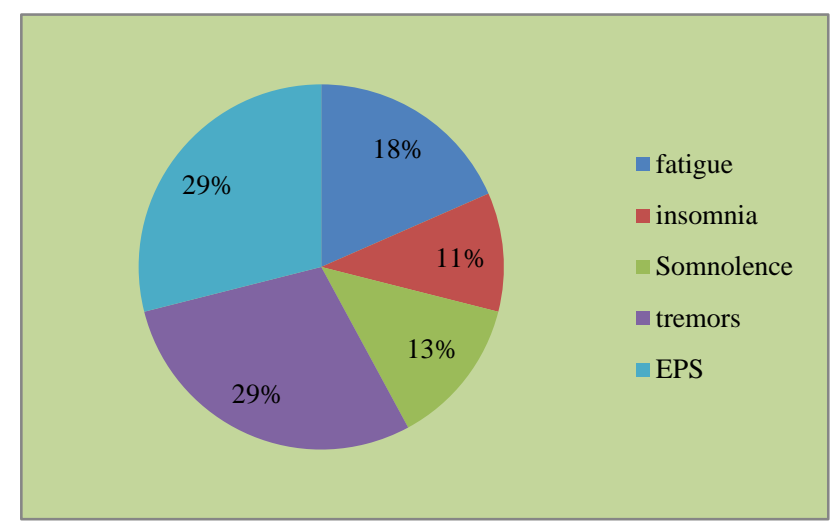

Figure 6: Adverse effects in haloperidol group.

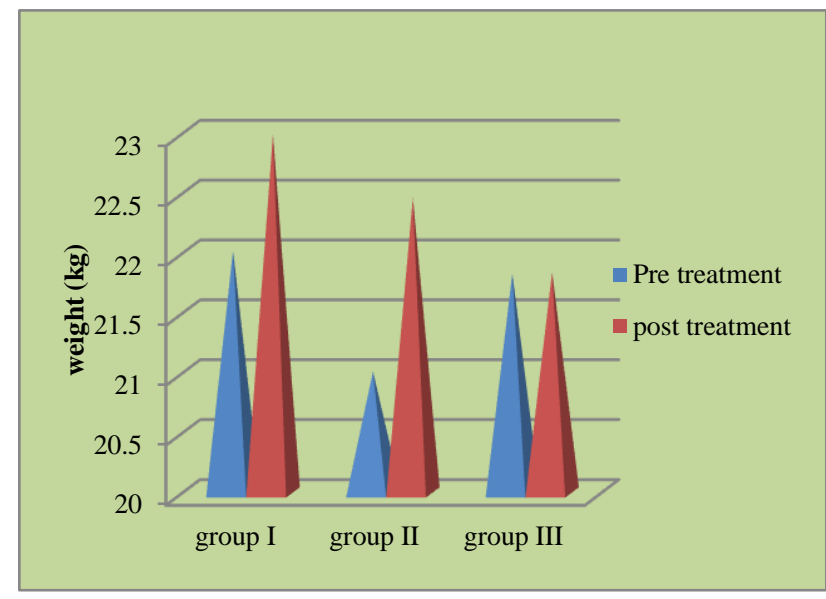

Figure 7: Change in weight among the study subjects.

\section{DISCUSSION}

Earlier study by Lieberman $\mathrm{AJ}$ et al. $^{7}$ found that significantly more olanzapine treated subjects completed the study compared to haloperidol group. In our study, medication adherence by pill count was better with atypical antipsychotics compared to typical drugs and these findings matched with study done by Lieberman et al. $^{7}$
In the present study there was statistically significant reduction in BARS score and SAS score in all three treatment groups. Earlier studies by Tollefson et al found that change in SAS score from baseline to end point reflected a 1-point improvement in extra pyramidal symptoms among olanzapine group and 1-point worsening among haloperidol treated patients. ${ }^{8}$

A similar pattern was seen with BARS score, where olanzapine treated patients score improved and haloperidol treated patients scores worsened from baseline. In the present study there was statistically significant reduction in AIMS score in haloperidol. Abnormal Involuntary Movements were not seen with risperidone and olanzapine, thus the score was 0 in both these groups. Similar studies by Tollefson et al showed the Abnormal Involuntary Movement Scale, research diagnostic criteria for tardive dyskinesia were used to define the comparative incidence rates of long-term treatment emergent tardive dyskinesia. ${ }^{8}$ The incidence of newly emergent tardive dyskinesia was statistically significantly lower among olanzapine treated patients than among haloperidol-treated patients.

Most common adverse drug reaction in our study was as follows: In risperidone group: weight gain, constipation, increased appetite, and nasal congestion. In olanzapine group: weight gain, increased appetite, constipation and dizziness. In haloperidol group: EPS and tremors, fatigue and Somnolence. The commonly observed EPS were tremors, abnormal gait, and dystonia. In the present study there was low occurrence of EPS because the patients were prophylactically given anti-cholinergic agents like trihexylphenidyl. The occurrence of EPS was comparatively more with haloperidol compared to risperidone and olanzapine treated patients. Antipsychotic induced EPS have been associated with the drugs which block D2 at the nigrostriatal pathway. A major advantage of atypical antipsychotics is their relative freedom from this group of side effects.

In addition atypical antipsychotics are not equal along this dimension, risperidone's risk is dose-related and olanzapine carries a comparatively lower risk of overt EPS because of its inherent anti-muscarinic action. With their decreased risk of EPS, it has been postulated that the atypical antipsychotics may carry a decreased risk of tardive dyskinesia, since sustained EPS have been identified as a risk factor for tardive dyskinesia. ${ }^{5,9}$

Weight gain has always been an issue with antipsychotics, but as a side effect it has historically been over shadowed by the risk of EPS. Atypical antipsychotics, as a class, carry a much lower risk of EPS but a much greater risk of weight gain. Olanzapine and clozapine seem particularly problematic in this respect. Mechanisms underlying this drug induced weight gain are not entirely clear; both the serotonin $5 \mathrm{HT}_{2 \mathrm{C}}$ and the histamine H1blocking activity of these drugs have been implicated. Patients with schizophrenia tend to have poor 
levels of nutrition, a $70 \%$ prevalence of smoking, and little or no preventative health care, so the cardiovascular risks associated with weight gain take on even greater importance. ${ }^{10-12}$

Earlier studies have demonstrated moderate weight gain with Risperidone and significant weight gain with Olanzapine. ${ }^{13,14}$ The finding that Olanzapine causes significant weight gain than Risperidone found in the present study has been earlier reported by Lee et al. ${ }^{15}$ and conley RR et al. ${ }^{16}$ However Basson et al. ${ }^{12}$ observed that Olanzapine and Risperidone did not differ in their propensity to cause weight gain.

In present study treatment adherence was better with Olanzapine than Respiridone and Haloperidone group. Dropout rates were more in haloperidol group.

The present study has several limitations. No effort is taken to address correlation of socioeconomic status, family history of mental illness and age distribution of patient with that of treatment adherence. No effort is taken to study long term cardiovascular disease mortality due to increased weight gain. Sample size of present study is small, hence further studies with large sample size is needed to confirm the results of present study.

\section{ACKNOWLEDGEMENT}

We are thankful to Dr. C.R. Jayanthi (professor and head, department of pharmacology, BMCRI), Dr. H. Chandrashekar (professor and head, department of psychiatry, Victoria hospital, Bangalore) for their kind support thought the study. We are also thankful to Dr. Rekha, Dr. Manjula, for their continuous cooperation during present study.

\section{Funding: No funding sources}

Conflict of interest: None declared

Ethical approval: Not required

\section{REFERENCES}

1. Gelder MG, Lopez-Ibor. JJ, Andreasen N, editors. New Oxford Textbook of Psychiatry. Volume 1, 2ed. New York: Oxford university press; 2000:567-636.

2. Gosh A, Chakraborty K, Mattoo SK. Newer molecule in the treatment of schizophrenia: A clinical update. Indian journal of Pharmacology. 2011;43(2):105-12.

3. Sharma HL, Sharma KK,editors. Principles of Pharmaclogy. 2nd edition. Paras publication; 2011:451-460.

4. Lieberman AJ, Tollefson G, Tolen M, Dr. P.H, Green AI, Gur RE et al, Comparative efficacy and safety of atypical antipsychotic drugs in first-episode psychosis: A randomized, double blind trial of olanzapine versus haloperidol. American Journal of Psychiatry. 2003;160:1396-404.

5. Bruton LL, Lazo JS, Parker KL, editors. Goodman and Gillman's The Pharmacological Basis of Therapeutics. 10th ed. New York: McGraw hill; 2001:485-507.

6. Kannabiran M, Singh V. Metabolic syndrome and atypical antipsychotic: A selective literature review. German journal of psychiatry. 2008;11:111-22.

7. Lieberman AJ, Tollefson G, Tolen M, Dr. P.H, Green AI, Gur RE et al, Comparative efficacy and safety of atypical antipsychotic drugs in first-episode psychosis: A randomized, double blind trial of olanzapine versus haloperidol. American Journal of Psychiatry. 2003;160:1396-404.

8. Tollefson D G et al. Olanzapine versus Haloperidol in the Treatment of Schizophrenia and Schizoaffective and Schizophreniform Disorders: Results of an International Collaborative Trial. American Journal of Psychiatry. 1997;154:457-46.

9. Katzung BG, Masters SB, Trevors AJ. Basic and Clinical Pharmacology. 11th ed. New York: Tata McGraw Hill Education Private Limited; 2009: 665669.

10. Kapur S and Remington G. Atypical Antipsychotics: New Directions and New Challenges in the Treatment of Schizophrenia. Annual Review of Medicine. 2001;52:503-17.

11. Allison DB, Mentor JL, Moonseong H, Chandler LP, Cappelleri JC, Infante MC and Weiden PJ, Antipsychotic-Induced Weight Gain: A Comprehensive Research Synthesis American Journal of Psychiatry. 1999;156:1686-96.

12. Basson BR, Kinon BJ, Taylor CC, Szymanski KA, Gilmore JA, Tollefson GD. Factors influencing acute weight change in patients with Schizophrenia treated with olanzapine, Haloperidol, or risperidone. Journal of Clinical Psychiatry. 2001;62(4):231-8.

13. Wetterling T. Body weight gain with atypical antipsychotics. A comparative review. Drug Safety. 2001;24(1):59-73.

14. Haddad P. Weight change with atypical antipsychotics in the treatment of Schizophrenia. Journal of Psychopharmacology. 2005;19:16-27.

15. Lee E, Leung CM, Wong E. Atypical antipsychotics and weignt gain in Chinese patients: A Comparision of olanzapine and risperidone. Journal of Clinical Psychiatry. 2004:65-66.

16. Conley RR and Mahmoud R. A Randomized DoubleBlind Study of Risperidone and Olanzapine in the Treatment of Schizophrenia or Schizoaffective Disorder. American Journal of Psychiatry. 2001;158:765-74.

Cite this article as: Lavanya N, Madalageri NK. Safety and treatment adherence of commonly prescribed typical and atypical antipsychotics in schizophrenic patients in a tertiary care hospital. Int J Basic Clin Pharmacol 2016;5:2407-17. 


\section{Annexure 1}

\section{Abnormal Involuntary Movement Scale (AIMS):}

Scoring Procedure: For the movement ratings (the first three categories below), rate the highest severity observed.

$0=$ none, $1=$ minimal (may be extreme normal), $2=$ mild, $3=$ moderate, $4=$ severe .

According to the original AIMS instructions, one point is subtracted if movements are seen only on activation, but not all investigators follow that convention.

\begin{tabular}{|c|c|}
\hline $\begin{array}{l}\text { Muscles of facial expression } \\
\text { e.g., movements of forehead, eyebrows, periorbital area, cheeks. Include frowning, blinking, } \\
\text { grimacing of upper face. }\end{array}$ & $\begin{array}{l}0 \\
1 \\
2 \\
3 \\
4\end{array}$ \\
\hline $\begin{array}{l}\text { Lips and perioral area } \\
\text { e.g., puckering, pouting, smacking. }\end{array}$ & $\begin{array}{l}0 \\
1 \\
2 \\
3 \\
4\end{array}$ \\
\hline $\begin{array}{l}\text { Jaw } \\
\text { e.g., biting, clenching, chewing, mouth opening, lateral movement. }\end{array}$ & $\begin{array}{l}0 \\
1 \\
2 \\
3 \\
4\end{array}$ \\
\hline $\begin{array}{l}\text { Tongue } \\
\text { Rate only increase in movement both in and out of mouth, not Inability to sustain movement. }\end{array}$ & $\begin{array}{l}0 \\
1 \\
2 \\
3 \\
4\end{array}$ \\
\hline $\begin{array}{l}\text { Upper (arms, wrists, hands, fingers) } \\
\text { Include movements that are choreic (rapid, objectively purposeless, irregular, spontaneous) or } \\
\text { athetoid (slow, irregular, complex, serpentine). Do not include tremor (repetitive, regular, } \\
\text { rhythmic movements). }\end{array}$ & $\begin{array}{l}0 \\
1 \\
2 \\
3 \\
4\end{array}$ \\
\hline $\begin{array}{l}\text { Lower (legs, knees, ankles, toes) } \\
\text { e.g., lateral knee movement, foot tapping, heel dropping, foot squirming, inversion and eversion } \\
\text { of foot. }\end{array}$ & $\begin{array}{l}0 \\
1 \\
2 \\
3 \\
4\end{array}$ \\
\hline $\begin{array}{l}\text { Neck, shoulders, hips } \\
\text { e.g., rocking, twisting, squirming, pelvic gyrations. Include diaphragmatic movements. }\end{array}$ & $\begin{array}{l}0 \\
1 \\
2 \\
3 \\
4\end{array}$ \\
\hline Severity of abnormal movements & $\begin{array}{l}0 \\
1 \\
2 \\
3 \\
4\end{array}$ \\
\hline Incapacitation due to abnormal movements & $\begin{array}{l}0 \\
1 \\
2 \\
3 \\
4\end{array}$ \\
\hline $\begin{array}{l}\text { Patient's awareness of abnormal movements } \\
0 . \text { no awareness } \\
\text { 1. aware, no distress }\end{array}$ & $\begin{array}{l}0 \\
1\end{array}$ \\
\hline
\end{tabular}




\begin{tabular}{|ll|}
\hline 2. aware, mild distress & 2 \\
3. aware, moderate distress & 3 \\
4. aware, severe distress & 4 \\
\hline Current problems with teeth and/or dentures & no \\
\hline Does patient usually wear dentures? & yes \\
\hline
\end{tabular}

\section{Annexure 2}

\section{Barnes Akathisia Rating Scale (BARS)}

Instructions: Patient should be observed while they are seated, and then standing while engaged in neutral conversation (for a minimum of two minutes in each position). Symptoms observed in other situations, for example while engaged in activity on the ward, may also be rated. Subsequently, the subjective phenomena should be elicited by direct questioning.

\section{Objective}

0 Normal, occasional fidgety movements of the limbs

1 Presence of characteristic restless movements: shuffling or tramping movements of the legs/feet, or swinging of one leg while sitting, and/or rocking from foot to foot or "walking on the spot" when standing, but movements present for less than half the time observed.

2 Observed phenomena, as described in (1) above, which are present for at least half the observation period

3 Patient is constantly engaged in characteristic restless movements, and/or has the inability to remain seated or standing without walking or pacing, during the time observed.

\section{Subjective}

Awareness of restlessness:

0 Absence of inner restlessness

1 Non-specific sense of inner restlessness

2 The patient is aware of an inability to keep the legs still, or a desire to move the legs, and/or complains of inner restlessness aggravated specifically by being required to stand still.

3 Awareness of intense compulsion to move most of the time and/or reports strong desire to walk or pace most of the time.

Distress related to restlessness:

0 No distress

1 Mild

2 Moderate

3 Severe

\section{Global clinical assessment of Akathisia}

0 Absent. No evidence of awareness of restlessness. Observation of characteristic movements of akathisia in the absence of a subjective report of inner restlessness or compulsive desire to move the legs should be classified as pseudoakathisia 
1 Questionable. Non-specific inner tension and fidgety movements

2 Mild akathisia. Awareness of restlessness in the legs and/or inner restlessness worse when required to stand still. Fidgety movements' present, but characteristic restless movements of akathisia not necessarily observed. Condition causes little or no distress.

3 Moderate akathisia. Awareness of restlessness as described for mild akathisia above, combined with characteristic restless movements such as rocking from foot to foot when standing. Patient finds the condition distressing

4 Marked akathisia. Subjective experience of restlessness includes a compulsive desire to walk or pace. However, the patient is able to remain seated for at least five minutes. The condition is obviously distressing.

5 Severe akathisia. The patient reports a strong compulsion to pace up and down most of the time. Unable to sit or lie down for more than a few minutes. Constant restlessness which is associated with intense distress and insomnia.

\section{Annexure 3}

\section{Simpson-Angus Scale (SAS)}

\section{GAIT}

\section{$0=$ Normal}

$1=$ Diminution in swing while the patient is walking

$2=$ Marked diminution in swing with obvious rigidity in the arm

$3=$ Stiff gait with arms held rigidly before the abdomen

$4=$ Stopped shuffling gait with propulsion and retropulsion

\section{Arm Dropping}

$0=$ Normal, free fall with loud slap and rebound

$1=$ Fall slowed slightly with less audible contact and little rebound

$2=$ Fall slowed, no rebound

3 = Marked slowing, no slap at all

$4=$ Arms fall as though against resistance; as though through glue

\section{Shoulder Shaking}

$0=$ Normal

$1=$ Slight stiffness and resistance

$2=$ Moderate stiffness and resistance

$3=$ Marked rigidity with difficulty in passive movement

4 = Extreme stiffness and rigidity with almost a frozen shoulder

\section{Elbow Rigidity}

$0=$ Normal

$1=$ Slight stiffness and resistance

2 = Moderate stiffness and resistance

$3=$ Marked rigidity with difficulty in passive movement

$4=$ Extreme stiffness and rigidity with almost a frozen shoulder

\section{Wrist Rigidity or Fixation of position}

\section{$0=$ Normal}

$1=$ Slight stiffness and resistance

$2=$ Moderate stiffness and resistance

$3=$ Marked rigidity with difficulty in passive movement

$4=$ Extreme stiffness and rigidity with almost a frozen shoulder

\section{Leg Pendulousness}

$0=$ The legs swing freely

$1=$ Slight diminution in the swing of the legs

$2=$ Moderate resistance to swing

$3=$ Marked resistance and damping of swing

4 = Complete absence of swing

\section{Head Dropping}

$0=$ The head falls completely with a good thump as it hits the table

$1=$ Slight slowing in fall, mainly noted by lack of slap as head meets the table

$2=$ Moderate slowing in the fall quite noticeable to the eye

$3=$ Head falls stiffly and slowly 


\begin{tabular}{|l|}
\hline $4=$ Head does not reach the examining table \\
\hline Glabella Tap \\
\hline $0=0-5$ blinks \\
$1=6-10$ blinks \\
$2=11-15$ blinks \\
$3=16-20$ blinks \\
$4=21$ and more blinks \\
\hline Tremor \\
\hline $0=$ Normal \\
$1=$ Mild finger tremor, obvious to sight and touch \\
$2=$ Tremor of hand or arm occurring spasmodically \\
$3=$ Persistent tremor of one or more limbs \\
$4=$ Whole body tremor \\
\hline Salivation \\
\hline $0=$ Normal \\
$1=$ Excess salivation to the extent that pooling takes place if the mouth is open and the tongue raised. \\
$2=$ When excess salivation is present and might occasionally result in difficulty in speaking \\
$3=$ Speaking with difficulty because of excess salivation \\
$4=$ Frank drooling \\
\hline
\end{tabular}

